\title{
De relatie tussen specialisme van keuzeco-schap en vervolgopleiding
}

\author{
W.M. Molenaar, J.J. Reinders, J. Cohen-Schotanus
}

\begin{abstract}
Samenvatting
Inleiding: In de Nederlandse discussie over het medisch opleidingscontinuüm wordt de mogelijkheid van een individueel in te vullen schakeljaar als overgang tussen de basis- en de vervolgopleiding genoemd. In het Groningse curriculum vormt het keuzeco-schap reeds een dergelijke overgang. Daarom werd de relatie tussen specialisatiekeuzes voor het keuzeco-schap en de vervolgopleiding geanalyseerd.
\end{abstract}

Materiaal en methoden: Telefonisch werd afgestudeerden die hun studie in 1992-1993 begonnen, gevraagd naar hun huidige specialisme, verkregen opleidingsplaats en specialisme van voorkeur. De gegevens werden vergeleken met de administratieve gegevens over hun keuzeco-schap. Van 283 afgestudeerden waren de gegevens compleet (82\% van het cohort), waarvan 196 een opleidingsplaats hadden verkregen.

Resultaten: Er was een verschuiving van grote klinische disciplines voor het keuzeco-schap (69\% vs. 2\% extramuraal) naar extramurale disciplines bij de latere werkkring (24\% vs. $28 \%$ klinisch). Van de artsen in opleiding meldde $95 \%$ te werken in hun specialisme van voorkeur, dat in meer dan de helft van de gevallen anders is dan het keuzeco-schap. Artsen in opleiding bij kindergeneeskunde $(n=11)$, interne $(n=21)$ of neurologie $(n=9)$ hadden in respectievelijk $100 \%, 81 \%$ en $78 \%$ van de gevallen in hetzelfde specialisme hun keuzeco-schap gedaan. Huisartsen in opleiding deden vooral interne geneeskunde en kindergeneeskunde.

Discussie: De relatie tussen de keuze voor het specialisme van het keuzeco-schap en (het verkrijgen van) een vervolgopleiding is niet eenduidig en er lijken verschillen te bestaan tussen specialismen. Een keuzeco-schap in een groot klinisch specialisme wordt wellicht gezien als brede basis voor een vervolgopleiding. (Molenaar WM, Reinders JJ, Cohen-Schotanus J. De relatie tussen specialisme van keuzeco-schap en vervolgopleiding. Tijdschrift voor Medisch Onderwijs 2004;23(1):23-29.)

\section{Inleiding}

In de discussies over de totale duur van de medische opleiding wordt in Nederland het schakeljaar als een mogelijkheid tot verkorting van het gehele medische opleidingscontinuüm genoemd. ${ }^{1}$ In het schakeljaar kunnen studenten in het kader van de basisopleiding elementen opnemen die korting kunnen opleveren voor hun vervolgopleiding. Hierbij wordt ervan uitgegaan dat studenten voor ogen hebben welke specialisatie ze ambiëren.
In het Groningse curriculum C2000 volgen alle studenten gedurende de laatste 2 jaar van de opleiding achtereenvolgens coschappen in de klinische disciplines, een 13 weken durend extramuraal co-schap (huisartsgeneeskunde en sociale geneeskunde) en tenslotte een 13 weken durend keuzeco-schap. Het keuzeco-schap heeft als voornaamste doel studenten zelfstandig als arts te leren werken en fungeert daarmee nadrukkelijk als overgang van medisch student naar beginnend arts. In 
de periode van het onderzoek werden aan studenten of begeleiders verder weinig specifieke instructies gegeven ten aanzien van het keuzeco-schap. De studenten hebben grote vrijheid in zowel de keuze van (sub)specialisme als van plaats van het keuzeco-schap. Een aantal keuzeco-schappen wordt standaard aangeboden, maar daarnaast kunnen studenten zelf initiatieven nemen. Voorwaarden voor goedkeuring van een keuzeco-schap zijn dat studenten (vrijwel) zelfstandig kunnen werken en dat zij worden gesuperviseerd door een praktiserend arts. Toetsing van het keuzeco-schap vindt enerzijds plaats door de begeleider die het dagelijks functioneren van de student beoordeelt en anderzijds door middel van een geschreven klinische les, die door een onafhankelijke beoordelaar getoetst wordt. In de periode 1998-2000 deed 15\% van de studenten het keuzeco-schap in het Academisch Ziekenhuis Groningen, 45\% in de affiliatieziekenhuizen en de rest elders in Nederland $(29 \%)$ of in het buitenland $(11 \%)$.

Om inzicht te krijgen in de relatie tussen de keuze van specialisme voor het keuzecoschap en de latere specialisatie is een inventarisatie gedaan onder 2 jaarcohorten Groningse studenten, 1-4 jaar na afstuderen. De vragen die hierbij werden gesteld luiden:

- Hoe is de verdeling over de specialismen ten tijde van het keuzeco-schap en 1-4 jaar na afstuderen?

- Wat is de relatie tussen de keuzes voor een specialisme voor het keuzeco-schap en voor de vervolgopleiding?

- Beïnvloedt het volgen van een keuzecoschap het verkrijgen van een opleidingsplaats in hetzelfde specialisme?

\section{Materiaal en methoden}

Uit de gegevens van de onderwijsadministratie zijn alle 345 studenten geïdentificeerd die in 1992 of 1993 in Groningen aan hun studie geneeskunde begonnen en die tussen mei 1998 en maart 2001 waren afgestudeerd. Hiervan bleken er 28 niet bereikbaar, 1 overleden en 14 weigerden medewerking. De overige 302 werd in een telefonische enquête in het voorjaar van 2002 gevraagd naar het specialisme waarin ze op dat moment werkzaam waren, of ze een opleidingsplaats hadden verkregen of een toezegging daarvoor en wat op dat moment hun specialisme van voorkeur was. Deze gegevens zijn vergeleken met de uit de administratie beschikbare gegevens over het keuzeco-schap van dezelfde studenten.

Van de geïnterviewden bleken er ten tijde van het interview 298 medisch werkzaam. Van 283 van deze studenten, 123 mannen en 160 vrouwen ( $82 \%$ van het oorspronkelijke cohort), waren volledige gegevens over het keuzeco-schap traceerbaar; 196 hiervan (87 mannen en 109 vrouwen) hadden een opleidingsplaats verkregen of een toezegging daarvoor. Er werd een kwantitatieve analyse gedaan van de specialismen van het keuzeco-schap, van de huidige werkkring voor het gehele cohort en voor de subgroep die een opleidingsplaats verkreeg. In de groep met een opleidingsplaats werden in een paarsgewijze analyse de keuzes voor een specialisme voor het keuzeco-schap en de vervolgopleiding van individuele studenten vergeleken. Per specialisme werd berekend welk percentage van de artsen in opleiding eerder een keuzeco-schap in hetzelfde specialisme deed en, omgekeerd, welk percentage van de studenten dat een keuzeco-schap deed later in dit specialisme in opleiding kwam. 


\section{Resultaten}

De verdeling over de specialismen voor het keuzeco-schap en de latere werkkring De grote meerderheid van de studenten koos voor een keuzeco-schap in één van de grote klinische disciplines, met in totaal 69\% keuze voor interne geneeskunde, kindergeneeskunde, chirurgie, obstetrie \& gynaecologie of neurologie. Slechts weinigen deden een extramuraal keuzeco-schap: in totaal $2 \%$ in huisartsgeneeskunde, verpleeghuisgeneeskunde, arts voor verstandelijk gehandicapten, sociale geneeskunde, bedrijfsgeneeskunde of verzekerings-/keuringsarts. Ten tijde van het onderzoek bleek het percentage werkzaam binnen de grote klinische disciplines te zijn afgenomen tot 28 en dat in de extramurale gezondheidszorg te zijn toegenomen tot 24. Voor artsen met een opleidingsplaats is dit respectievelijk 35\% en 31\% (zie tabel 1).

\section{De relatie tussen de keuzes voor een specialisme voor het keuzeco-schap en de vervolgopleiding}

Er van uitgaande dat het verkrijgen van een opleidingsplaats een definitieve keuze voor een specialisme reflecteert, werd binnen de groep met een opleidingsplaats de relatie tussen het huidige specialisme en het specialisme van voorkeur geanalyseerd. Binnen deze groep gaf $95 \%$ aan dat het huidige specialisme hun voorkeur heeft, terwijl dit in slechts 38\% hetzelfde is als het specialisme van het keuzecoschap. Dit percentage neemt toe tot 49 wanneer aangrenzende specialismen als volgt gegroepeerd worden: interne geneeskunde met cardiologie, gastro-enterologie, longziekten en reumatologie, chirurgie met cardiopulmonale chirurgie, orthopedie, plastische chirurgie, urologie en kaakchirurgie en neurologie met neurochirurgie en psychiatrie.

\section{De invloed van het volgen van een} keuzeco-schap op het verkrijgen van een opleidingsplaats in hetzelfde specialisme

De vergelijking tussen het verkrijgen van een opleidingsplaats en het gedaan hebben van een keuzeco-schap is voor de grote klinische en extramurale specialismen weergegeven in tabel 2. Opvallend is dat alle studenten die een opleidingsplaats kindergeneeskunde kregen en een grote meerderheid bij interne geneeskunde en neurologie in dezelfde specialismen hun keuzeco-schap hadden gedaan, maar velen die dit ook deden waren niet in opleiding gekomen. Er werd niet geanalyseerd of er sprake was van dezelfde opleidingsinstelling voor het keuzecoschap en de vervolgopleiding. Drie van de vier studenten die hun keuzeco-schap bij huisartsgeneeskunde deden kregen hier ook een opleidingsplaats, maar met hen vele anderen. Geen van de artsen die in opleiding kwam bij de sociale geneeskunde deed hierin een keuzeco-schap en omgekeerd, geen van de keuzeco's kwam in opleiding.

\section{Discussie}

In het beschreven onderzoek is een kwantitatieve analyse gemaakt van de relatie tussen de keuze die studenten maakten voor hun keuzeco-schap in vergelijking tot hun werkkring en de keuze voor een vervolgopleiding in de eerste jaren na afstuderen.

\section{Beperkingen van het onderzoek}

$\mathrm{Er}$ is niet gevraagd naar de motivatie van de keuzes van studenten en het onderzoek werd verricht onder studenten van één faculteit geneeskunde. Daar staat tegenover dat van een groot deel van het cohort $(82 \%)$ volledige gegevens werden verkregen. Er is geen reden om aan te nemen dat deze studenten niet representatief zijn 
Tabel 1. Verdeling over de specialismen tijdens het keuzeco-schap en 1-4 jaar daarna, al dan niet in opleiding.

\begin{tabular}{|c|c|c|}
\hline & Keuzeco-schap & Werkkring $1-4$ jaar later * \\
\hline Anesthesiologie & 7 & $7(7)$ \\
\hline Bedrijfsarts & 0 & $8(6)$ \\
\hline Cardiologie & 5 & $12(8)$ \\
\hline Cardiopulmonale chirurgie & 3 & 0 \\
\hline Chirurgie & 33 & $16(10)$ \\
\hline Consultatiebureau & 0 & $7(1)$ \\
\hline Dermatologie & 4 & $1(1)$ \\
\hline Gastro-enterologie & 2 & $1(1)$ \\
\hline Geriatrie & 2 & $1(1)$ \\
\hline Huisartsen & 4 & $46(45)$ \\
\hline Interne geneeskunde & 79 & $34(21)$ \\
\hline Kaakchirurgie & 2 & $3(3)$ \\
\hline KNO & 4 & $4(3)$ \\
\hline Kindergeneeskunde & 44 & $19(11)$ \\
\hline Klinische genetica & 1 & 0 \\
\hline Longziekten & 1 & $10(9)$ \\
\hline Microbiologie & 0 & $1(1)$ \\
\hline Militair arts & 0 & $4(0)$ \\
\hline Neurochirurgie & 2 & 0 \\
\hline Neurologie & 20 & $10(9)$ \\
\hline Nucleaire geneeskunde & 1 & $1(1)$ \\
\hline Obstetrie \& gynaecologie & 19 & $11(7)$ \\
\hline Oogheelkunde & 1 & 0 \\
\hline Orthopedie & 12 & $12(8)$ \\
\hline Pathologie & 2 & $1(1)$ \\
\hline Plastische chirurgie & 7 & $2(1)$ \\
\hline Poortarts & 2 & $3(1)$ \\
\hline Psychiatrie & 12 & $18(13)$ \\
\hline Radiologie & 3 & $4(4)$ \\
\hline Radiotherapie & 1 & $4(3)$ \\
\hline Reumatologie & 0 & $1(0)$ \\
\hline Revalidatie & 6 & $6(5)$ \\
\hline Sociale geneeskunde & 1 & $5(5)$ \\
\hline Tropenarts & 2 & 0 \\
\hline Urologie & 0 & $4(2)$ \\
\hline Verpleeghuisgeneeskunde & 0 & $3(3)$ \\
\hline Verstandelijk gehandicapten & 0 & $1(1)$ \\
\hline Verzekeringsarts/keuringsarts & 0 & $5(1)$ \\
\hline Vrijstelling & 1 & \\
\hline Overig & 0 & $18(3)$ \\
\hline Totaal & 283 & $283(196)$ \\
\hline
\end{tabular}

* De getallen tussen haakjes geven de aantallen studenten weer die een opleidingsplaats verkregen. 
Tabel 2. Relatie tussen specialisme van het keuzeco-schap en dat van een opleidingsplaats bij studenten die een opleidingsplaats verkregen in grote klinische of extramurale disciplines.

\begin{tabular}{lcccc}
\hline Specialisme & Keuzeco-schap $(\mathbf{n})$ & AGIO * $(\mathbf{n})^{\text {n }}$ & $\begin{array}{c}\text { \% AGIO's dat } \\
\text { keuzeco was in } \\
\text { hetzelfde } \\
\text { specialisme }\end{array}$ & $\begin{array}{c}\text { \% keuzeco's } \\
\text { dat AGIO werd } \\
\text { in hetzelfde } \\
\text { specialisme }\end{array}$ \\
\hline Interne geneeskunde & 79 & 21 & 81 & 22 \\
Chirurgie & 44 & 10 & 40 & 25 \\
Kindergeneeskunde & 33 & 11 & 100 & 12 \\
Neurologie & 20 & 9 & 78 & 35 \\
Obstetrie \& gynaecologie & 19 & 7 & 29 & 11 \\
Huisartsgeneeskunde & 4 & 45 & 6 & 75 \\
Sociale geneeskunde & 1 & 14 & 0 & 0 \\
\hline
\end{tabular}

* AGIO: assistent-geneeskundige in opleiding (inclusief toegezegde opleidingsplaats).

** = aantal AGIO's met hetzelfde specialisme voor keuzeco-schap/totaal aantal AGIO's in dit specialisme $\times 100$.

*** = aantal AGIO's met hetzelfde specialisme voor het keuzeco-schap/totaal aantal keuzeco's in dit specialisme $\times 100$.

voor het gehele cohort en er is geen aanleiding om aan te nemen dat Groningse studenten zich anders gedragen dan studenten van andere Nederlandse faculteiten. De bevindingen kunnen daarmee een indicatie geven van de doorstroom van studenten van de laatste fase van de basisopleiding naar de vervolgopleidingen.

\section{De verdeling over de specialismen ten tijde van het keuzeco-schap en 1-4 jaar na afstuderen}

De vergelijking tussen het specialisme van het keuzeco-schap en dat van de werkkring 1-4 jaar na afstuderen laat zien dat er een duidelijke verschuiving is van grote klinische specialismen naar de extramurale gezondheidszorg. Deze verschuiving en de relatief grote hoeveelheid recent afgestudeerden dat extramuraal werkzaam is, is in overeenstemming met eerdere studies in Nederland en daarbuiten. ${ }^{2-6}$

\section{De relatie tussen de keuzes voor een specialisme voor het keuzeco-schap en de vervolgopleiding}

De percentages studenten die een opleidingsplaats hadden verkregen (69\%), en bovendien in hun specialisme van voorkeur (95\%), zijn relatief hoog. Dit reflecteert vermoedelijk vooral de huidige Nederlandse arbeidsmarktsituatie, waarin een grote behoefte is aan artsen en waarin pas afgestudeerde artsen gemakkelijk een werkkring en een opleidingsplaats vinden (vergelijk Cohen-Schotanus et al. vs. De Graaf et al.).2-3 Desalniettemin was het specialisme van de vervolgopleiding slechts in $49 \%$ hetzelfde als dat van het keuzeco-schap of een direct gerelateerd (sub)specialisme. Een verklaring voor dit verschil zou kunnen liggen in de vrijwel ongelimiteerde keuzemogelijkheden voor het keuzeco-schap ten opzichte van een beperkter aantal opleidingsplaatsen. Gezien bovengenoemde arbeidsmarktsituatie zal dit echter geen sterke rol gespeeld hebben.

Een andere verklaring kan zijn dat studenten pas gevraagd werd naar hun specialisme van voorkeur op het moment dat zij een opleidingsplaats hadden verkregen. Een al dan niet uitgesproken, maar niet gehonoreerde andere keuze is op dat moment wellicht verdrongen (cognitieve dissonantie). Verder blijkt uit recent onderzoek dat sociale factoren als lange 
werktijden en onregelmatige diensten, inclusief nachtdiensten, een steeds sterkere rol gaan spelen bij carrièrekeuzes. ${ }^{7-8}$ Het kan goed zijn dat deze factoren gemakkelijker geaccepteerd worden voor een korte welomschreven periode zoals het keuzeco-schap dan als langdurig beroepsperspectief.

Tenslotte is studenten in dit onderzoek niet gevraagd naar de redenen van hun keuze voor het betreffende keuzeco-schap en of ze al een keuze voor een vervolgopleiding hadden gemaakt. Het kan zijn dat er bewust gekozen is voor een groot klinisch specialisme als 'brede basis'. Deze veronderstelling wordt gesteund door de bevinding dat van de 45 huisartsen in opleiding, 22 een keuzeco-schap interne geneeskunde deden, 10 kindergeneeskunde en slechts 3 huisartsgeneeskunde.

\section{De invloed van het volgen van een} keuzeco-schap op het verkrijgen van een opleidingsplaats in hetzelfde specialisme

De gegevens met betrekking tot het verkrijgen van een opleidingsplaats laten grote verschillen per specialisme zien. Opvallend is dat in de huidige groep hoge percentages van arts-assistenten in opleiding in de kindergeneeskunde, neurologie en interne geneeskunde ook in dit vak hun keuzeco-schap hadden gedaan. Dit suggereert dat binnen deze specialismen een keuzeco-schap de kans op een opleidingsplaats vergroot. Dit in tegenstelling tot de huisarts- en sociale geneeskunde. Voor de huisartsgeneeskunde is dit te verklaren door het beleid bij de betreffende disciplinegroep, waar studenten met een vaststaande keuze voor de huisartsgeneeskunde werd afgeraden hun keuzeco-schap in dit vak te doen en de beschikbare plaatsen werden gegeven aan twijfelaars en kandidaten voor andere vervolgopleidingen. Het grote aantal studenten dat ver- moedelijk reeds vroeg koos voor een opleiding huisartsgeneeskunde is in overeenstemming met eerdere observaties dat een keuze voor de huisartsgeneeskunde vroeg gemaakt wordt en relatief stabiel is. 68

\section{Conclusie, betekenis voor het beleid en verder onderzoek}

De huidige bevindingen laten zien dat studenten brede keuzes maken voor een keuzeco-schap. Dit lijkt goed aan te sluiten bij de suggesties van de projectgroep medisch opleidingscontinuüm om het schakeljaar te laten volgen door een brede basisvervolgopleiding, bijvoorbeeld in de snijdende disciplines. Op deze wijze kan een definitieve keuze voor een 'bovenbouw' specialisatie nog enige tijd uitgesteld worden. Om meer inzicht te krijgen in de overwegingen van studenten wordt thans een prospectieve studie verricht naar de motivatie van de keuzes van studenten voor hun keuzeco-schap en de verwachtingen ten aanzien van de invloed van het keuzeco-schap op de keuze voor en het verkrijgen van een opleidingsplaats.

\section{Literatuur}

1. Meijboom-de Jong B, Schmit Jongbloed LJ, Willemsen MC, editors. De arts van straks - een nieuw medisch opleidingscontinuüm. Utrecht: KNMG/ DMW-VSNU/VAZ/NVZ/LCVV; oktober 2002.

2. Cohen-Schotanus J, Huisjes HJ. De plaats op de arbeidsmarkt van artsen die in 1982 en 1983 in Groningen gingen studeren. Ned Tijdschr Geneeskd 1994;138(28):1434-7.

3. Graaff E de, Drop MJ, Post GJ, Roos KP de. Carrierevoorkeur en entree op de arbeidsmarkt van Maastrichtse basisartsen. Ned Tijdschr Geneeskd 1987; 131(38):1677-8.

4. Soethout MBM. De afgestudeerden van de medische faculteit der Vrije Universiteit. Med Contact 1991;35:1002-8.

5. Edwards C, Lambert TW, Goldacre MJ, Parkhouse J. Early medical career choices and eventual careers. Med Educ 1997;31(4):237-42.

6. Goldacre MJ, Lambert TW. Stability and change in career choices of junior doctors: postal questionnaire surveys of the United Kingdom qualifiers of 1993. Med Educ 2000;34(9):700-7. 
7. Dorsey ER, Jarjoura D, Rutecki GW. Influence of controllable lifestyle on recent trends in specialty choice by US medical students. JAMA 2003;290(9):1173-8.

8. Lambert TW, Davidson JM, Evans J, Goldacre MJ. Doctors' reasons for rejecting initial choices of specialties as long-term careers. Med Educ 2003;37 (4):312-8.

\section{De auteurs:}

Prof. dr. W.M. Molenaar is patholoog (n.p.) en stafmedewerker.

Drs. J.J. Reinders is psycholoog en projectmedewerker. Mw. dr. J. Cohen-Schotanus is psycholoog en afdelingshoofd.

\section{Summary}

Introduction: One of the issues in the discussion on the medical education continuum in the Netherlands is the transition from undergraduate training to postgraduate specialty training. Medical students in Groningen get their first taste of this transition in the elective clerkship at the end of the curriculum. We examined the relationship between the discipline of the elective clerkship and that of specialty training.

Material and methods: Graduates of the cohort entering medical school in 1992-1993 were interviewed by telephone about their current specialty, training position and preferred specialty. These data were compared with administrative data of the elective clerkships. Of 283 graduates for whom complete data were available (82\% of the cohort), 196 had obtained training positions.

Results: There was a shift between the major clinical disciplines for the elective clerkship (69\% vs. $2 \%$ primary care) to primary care for the current position (24\% vs. $28 \%$ clinical specialties). Of the graduates, $95 \%$ were currently in the specialty of their preference. For $<50 \%$ this corresponded with that of the elective clerkship. Of trainees in pediatrics $(n=11)$, internal medicine $(n=21)$ and neurology $(n=9), 100 \%, 81 \%$ and $78 \%$, respectively, had done the elective clerkship in the same specialty. Most trainees in general practice had done elective clerkships in internal medicine or pediatrics.

Discussion: The relationship between the discipline of the elective clerkship and specialty training is complicated and appears to differ between specialties. Students may regard an elective clerkship in one of the major clinical specialties as providing a broad basis for specialty training. (Molenaar WM, Reinders JJ, Cohen-Schotanus J. Does the choice of an elective clerkship predict specialty choice? Dutch Journal of Medical Education 2004;23(1):23-29.) 